\title{
Nina Bouraoui, Poupée bella
}

\section{Ilaria Vitali}

\section{(2) OpenEdition}

\section{Journals}

\section{Edizione digitale}

URL: http://journals.openedition.org/studifrancesi/35353

DOI: 10.4000/studifrancesi.35353

ISSN: 2427-5856

\section{Editore}

Rosenberg \& Sellier

\section{Edizione cartacea}

Data di pubblicazione: 1 novembre 2005

Paginazione: 463

ISSN: 0039-2944

\section{Notizia bibliografica digitale}

Ilaria Vitali, «Nina Bouraoui, Poupée bella», Studi Francesi [Online], 146 (XLIX | II) | 2005, online dal 30 novembre 2015, consultato il 19 avril 2021. URL: http://journals.openedition.org/studifrancesi/35353 ; DOI: https://doi.org/10.4000/studifrancesi.35353

\section{Questo documento è stato generato automaticamente il 19 avril 2021.}

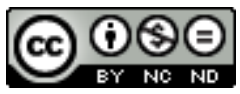

Studi Francesi è distribuita con Licenza Creative Commons Attribuzione - Non commerciale - Non opere derivate 4.0 Internazionale. 


\title{
Nina Bouraoui, Poupée bella
}

\author{
Ilaria Vitali
}

\section{NOTIZIA}

NINA BOURAOUI, Poupée bella, Paris, Stock, 2004, pp. 140.

1 Di padre algerino e madre francese, Nina Bouraoui ha affrontato in tutti i suoi romanzi la questione identitaria, il tema del biculturalismo, il problema di una doppia eredità linguistica e culturale. Tuttavia è con il suo ultimo romanzo, Poupée bella, che lo fa, per la prima volta, in modo esplicitamente autobiografico. A partire da La voyeuse interdite, Nina Bouraoui ha abituato il lettore a romanzi criptici, dalla scrittura violenta, a tratti ansiogena, alla costante ricerca di una nuova voce. Ritorna ora con un romanzo che racconta di vite «interiori ed esteriori»: un diario intimo, autentica autobiografia, che narra la vita dell'autrice tra la Svizzera, la Francia e l'Algeria, concentrando il suo sguardo tormentato sul mistero dell'universo femminile. Poupée bella è un diario intimo dalla sovragrafia sorprendente, che vuole esaltare la scrittura come volontà e bisogno vitale. Scrive Bouraoui: «Aimer, Écrire, sont les deux actes fondateurs de ma vie, inséparables, l'un nourrissant toujours l'autre, l'un racontant toujours l'autre» (p. 32).

Ritornano tutti i motivi topici che hanno segnato i cinque romanzi precedenti di Bouraoui: il mito dell'androgino (così caro a Khatibi e alla letteratura magrebina in generale) o il desiderio di sangue, che avevano trasformato Bouraoui in un'epigona di Boudjedra. La violence scripturaire è inevitabilmente presente nell'evocazione di un paese, l'Algeria, che l'autrice stessa definisce «tellurico». Tuttavia, Bouraoui afferma di volersi staccare, con questo romanzo, dalle etichette che l'hanno classificata, di volta in volta, come «francese d'origine algerina», «francofona», «magrebina». Poupée bella è, come lo definisce l'autrice, un breviario amoroso che racconta il risveglio dei sensi, fatto di brevi notazioni e scandito dal ritmo di un «je» lirico, che fotografa le emozioni come autentiche istantanee. Un canto in prosa, un romanzo autobiografico che vuole essere allo stesso tempo confessione e finzione, diario intimo e opera narrativa, nel 
tentativo di trascendere la singolarità dell'esperienza personale all'insegna dell'universalità. 